mantuvo hasta el año 2001, con una duración promedio de 31 años (desviación estándar de 1,3 años).

Las mujeres que cumplían los requisitos para participar en esta investigación $(n=7$ 302) se clasificaron en cuatro grupos, según su riesgo de ECV en el momento de incorporarse al estudio. Se definió de bajo riesgo la presencia de valores favorables de los siguientes indicadores: presión arterial sistólica (PAS) de $120 \mathrm{~mm} \mathrm{Hg}$ o menos y presión arterial diastólica (PAD) de $80 \mathrm{~mm} \mathrm{Hg}$ o menos sin tomar medicamentos antihipertensivos; concentraciones de colesterol séricas por debajo de $200 \mathrm{mg} / \mathrm{dL}$ ( $\leq$ $5,17 \mathrm{mmol} / \mathrm{L}$ ) sin tomar medicamentos reductores del colesterol; índice de masa corporal (IMC) menor de 25,0; no ser diabético; y no fumar.

Las participantes con algún riesgo se clasificaron en: 1) las que no tenían factores de riesgo, pero presentaban al menos un indicador con valores desfavorables (definidos como: PAS entre 121 y 139 mm Hg y PAD entre 81 y $89 \mathrm{~mm} \mathrm{Hg}$ sin tomar medicamentos antihipertensivos; concentraciones de colesterol séricas entre 200 y $239 \mathrm{mg} / \mathrm{dL}$ [entre 5,17 y $6,18 \mathrm{mmol} / \mathrm{L}]$ sin tomar medicamentos reductores del colesterol; e IMC entre 25,0 y 29,9); 2) las que tenían solamente un factor de riesgo; y 3 ) las que tenían más de uno de los siguientes indicadores: PAS $\geq 140 \mathrm{~mm} \mathrm{Hg}$ o PAD $\geq 90 \mathrm{~mm} \mathrm{Hg}$ o tomaban medicamentos antihipertensivos; concentraciones de colesterol séricas $\geq 240 \mathrm{mg} / \mathrm{dL}(\geq 6,21 \mathrm{mmol} / \mathrm{L})$ o tomaban medicamentos reductores del colesterol; IMC $\geq 30,0$; tenían diabetes; o fumaban. Los entrevistadores tomaron nota de la raza de cada participante y de su pertenencia a un determinado grupo étnico con vistas a investigar las causas de que en los Estados Unidos la tasa de ECV en personas de la raza negra sea mayor que la de las personas de raza blanca.

De las 7302 mujeres jóvenes estudiadas, 1469 $(20,1 \%)$ se clasificaron como de bajo riesgo, mientras que la mayoría $(58,5 \%)$ tenía al menos un factor de riesgo elevado. Las mujeres con bajo riesgo tendían a ser más jóvenes, de raza blanca y mejor instruidas. Durante los 31 años de seguimiento ocurrieron 469 muertes, de ellas 94 por ECV y 47 por EIC.

Según los resultados del análisis con múltiples variables, todos los factores de riesgo relacionados con la mortalidad por EIC y ECV estuvieron asociados de manera individual con el tabaquismo y con valores elevados de IMC.

Las tasas de mortalidad por EIC ajustadas por la edad (por 10000 años-persona) fueron similares en el grupo de mujeres con bajo riesgo $(1,5)$ y el grupo de mujeres que no presentaban factores de riesgo, pero tenían al menos un indicador con valores desfavorables $(1,7)$. Por su parte, estas tasas fueron mucho menores que la de las mujeres que pre- sentaban solamente un factor de riesgo $(5,0)$ y la de las que tenían al menos dos factores de riesgo elevados $(9,1)$. Esta correlación fue similar para las tasas de mortalidad por ECV y para la mortalidad general. Después de hacer ajustes según la edad, la raza y alteraciones electrocardiográficas menores, las razones de riesgo instantáneo para la mortalidad general durante los 31 años de seguimiento fueron menores en las mujeres con bajo riesgo y aumentó a medida que aumentaba el número de factores de riesgo elevados.

La razón de riesgo instantáneo de mortalidad por ECV ajustada según múltiples variables en mujeres de bajo riesgo en comparación con las mujeres con al menos dos factores de riesgo elevados fue de 0,19 (intervalo de confianza de 95\%: 0,08 a 0,45). Se encontró un patrón similar para la mortalidad general y para la mortalidad por EIC, tanto en mujeres de raza negra como en las de raza blanca.

Estos resultados demuestran la importancia de que las mujeres jóvenes mantengan un perfil de bajo riesgo cardiovascular con vistas a reducir la mortalidad general por EIC y por ECV a largo plazo, algo similar a lo observado en hombres jóvenes y en hombres y mujeres de edad madura. Además, se demuestra que en personas que presentan un menor riesgo en las etapas más tempranas de la vida, se reducen las tasas de EIC y ECV. Los resultados presentados destacan la importancia de poner en marcha políticas nacionales centradas en la prevención y el control de los principales factores de riesgo de ECV, mediante la promoción de estilos de vida sanos desde las etapas más tempranas de la vida. (Daviglus ML, et al. Favorable cardiovascular risk profile in young women and long-term risk of cardiovascular and all-cause mortality. JAMA. 2004;292(13):1588-92).

\section{Características clínicas, epidemiológicas y ambientales del primer brote de síndrome pulmonar por hantavirus en América Central}

El síndrome pulmonar por hantavirus (SPH) es una enfermedad infecciosa caracterizada por síntomas generales, como fiebre, mialgia y dolor de cabeza, seguidos de disnea, edema pulmonar no cardiogénico, hipotensión arterial e insuficiencia cardiorrespiratoria. La tasa de mortalidad puede llegar al $52 \%$ de los casos. Los hallazgos de laboratorio más frecuentes que acompañan a esta enfermedad son la elevación del hematocrito y la leucocitosis con presencia de inmunoblastos y trombocitopenia. El SPH es una afección viral provocada por especies del género Hantavirus y se transmite por roedores de la familia Muridae, subfamilia Sigmodontinae. Las personas se infectan 
por la inhalación de heces, orina o saliva de roedores portadores del virus, aunque también se ha documentado la transmisión por contacto directo con personas infectadas.

El SPH se identificó por primera vez en 1993 durante un brote de una enfermedad respiratoria grave en los Estados Unidos. Desde entonces también se ha detectado y confirmado en seis países de América del Sur: Argentina, Bolivia, Brasil, Chile, Paraguay y Uruguay. Entre las especies de hantavirus aisladas en la Región se encuentran el virus Andes (Argentina, Bolivia, Chile y Uruguay), el virus Bermejo (Bolivia), el virus Juquitiba (Brasil), el virus Laguna Negra (Bolivia y Paraguay), el virus Lechiguanas (Argentina) y el virus Orán (Argentina).

En febrero de 2000, las autoridades sanitarias de Panamá informaron de un foco de una enfermedad respiratoria aguda grave en personas que residían en el distrito de Las Tablas, provincia de Los Santos, entre diciembre de 1999 y febrero de 2000. El análisis de la secuencia genómica del virus aislado de las muestras de suero de las personas y de tejidos de los roedores circundantes demostró que la causa de este brote de SPH era una nueva especie de hantavirus, denominada virus Choclo. En este artículo se resumen las características clínicas, epidemiológicas y ambientales de ese brote infeccioso.

Se definieron como casos probables de $\mathrm{SPH}$ los que presentaban fiebre (temperatura $\geq 38,3^{\circ} \mathrm{C}$ ) y disnea aguda idiopática que requiriera de oxigenación mecánica, y manifestaciones radiográficas de síndrome de disnea aguda o de infiltrados intersticiales en ambos pulmones. También se consideraron casos probables de SPH los pacientes con afecciones respiratorias de causa desconocida que condujeran a la muerte, con diagnóstico posmortem de edema pulmonar no cardiogénico sin causa identificable. Se consideraron casos confirmados los que presentaban una enfermedad clínicamente compatible con $\mathrm{SPH}$, con anticuerpos de la clase IgM específicos contra hantavirus en muestras de suero tomadas en la fase aguda de la enfermedad, homología nucleotídica con hantavirus mediante transcripción inversa y reacción en cadena de la polimerasa, o antígenos específicos de hantavirus detectados mediante técnicas de inmunohistoquímica.

Se examinaron y entrevistaron los pacientes ingresados con síntomas de SPH en dos hospitales de la ciudad de Panamá y uno del distrito de Las Tablas, y se investigaron retrospectivamente los posibles casos de SPH a partir de agosto de 1999 en esos hospitales. Se revisaron las historias clínicas de los pacientes ingresados en otros hospitales de la provincia de Las Tablas con indicios de SPH.

Con el objetivo de determinar la prevalencia de la infección por hantavirus en los hogares y ve- cindarios de los pacientes con SPH confirmado, se realizó un tamizaje serológico para la detección de anticuerpos contra hantavirus en las comunidades de los distritos de Las Tablas y Guarare donde vivían. También se investigó la presencia de anticuerpos contra hantavirus en el personal sanitario que atendió los casos confirmados de SPH en el principal hospital de la ciudad de Panamá, con vistas a evaluar la transmisión por contacto directo.

Se estudiaron los tejidos (hígado, riñón, bazo, pulmón y corazón) de pequeños mamíferos de la zona que pudieran ser hospederos o trasmisores de hantavirus.

Las manifestaciones clínicas de la enfermedad pulmonar en los pacientes con SPH en Panamá fueron diversas. Hubo casos graves que requirieron de entubación y apoyo cardiovascular, y casos con síntomas moderados. También se observaron manifestaciones extrapulmonares, como afecciones hepatobiliares, hemorragias y secuelas en el sistema nervioso central. La tasa de mortalidad entre los casos fue variable $(0 \%$ en 9 casos confirmados y $25 \%$ en otra serie de 12 casos), pero mucho menor que la encontrada en casos confirmados de SPH en Chile (54\%) y los Estados Unidos (52\%).

La prevalencia de anticuerpos contra hantavirus en los hogares y vecindarios de los casos confirmados fue de $13 \%$, similar a la encontrada en Paraguay, pero mayor que la observada en Chile y en los Estrados Unidos. No se observó que hubiera concentración de los casos de $\mathrm{SPH}$ ni de personas seropositivas en un mismo hogar. Solo $13 \%$ de las personas con anticuerpos contra hantavirus manifestaron haber tenido alguna enfermedad con fiebre después de los primeros días de diciembre de 1999 y ninguno informó haber enfermado con signos y síntomas compatibles con SPH, lo que podría indicar que la enfermedad pudo transcurrir con manifestaciones ligeras.

No se demostró que esta infección se transmitiera por contacto directo, aunque esta forma de transmisión parece haber ocurrido durante los brotes causados por el virus Andes en Argentina y Chile a finales de la década de 1990.

La información climática de la provincia de Los Santos demostró claramente que hubo un considerable aumento de las precipitaciones entre septiembre y octubre de 1999, en comparación con períodos similares de años anteriores. Este patrón atípico puede haber ocasionado un aumento en la población de roedores.

En cuanto a los posibles transmisores de la enfermedad, se encontraron roedores de la especie Oligoryzomys fulvescens —el reservorio más probable del virus Choclo- entre la hierba cercana a los asentamientos humanos y en los pastos del ganado. La secuencia nucleotídica de los virus aislados del 
tejido de estos roedores fue idéntica a la de los virus aislados de las muestras de pacientes.

Estos resultados, que documentan el primer brote de SPH en América Central — causado por una nueva especie de hantavirus, el virus Choclo-, subrayan la necesidad de continuar las campañas educacionales que promueven la limpieza adecuada de los excrementos de roedores, la eliminación de ratas y ratones de las viviendas, así como de otras medidas que conduzcan a la reducción del riesgo de infección por hantavirus. (Bayard V, et al. Outbreak of hantavirus pulmonary syndrome, Los Santos, Panama, 1999-2000. Emerg Infect Dis [serial on the Internet]. 2004;10(9):[29 pantallas]. Hallado en: http:/ /www.cdc.gov/ncidod/EID/vol10no9/040143.htm).

\section{4. ${ }^{0}$ Seminario Científico del Centro Nacional de Investigaciones Científicas}

Fecha: 27 a 30 de junio de 2005

Lugar: Palacio de Convenciones, La Habana, Cuba

Cada cinco años el Centro Nacional de Investigaciones Científicas (CNIC) de La Habana, Cuba, celebra este congreso, donde se reúnen especialistas nacionales e internacionales dedicados a la ciencia, la tecnología y el medio ambiente. Los temas tratados en esta oportunidad abarcan una gama muy amplia, desde los relacionados con la protección ambiental hasta los que se vinculan más estrechamente con la salud. Entre estos últimos se encuentran, por ejemplo, la elaboración de vacunas; los trastornos neurolingüísticos y psiquiátricos; la fonoaudiología; los sistemas para el diagnóstico rápido en microbiología; las aplicaciones de la nanotecnología a la medicina y la industria farmacéutica; y el desarrollo, la evaluación y las aplicaciones clínicas de biomateriales. El congreso ofrece la oportunidad de exponer nuevos productos y tecnologías de la industria médica y farmacéutica, y habrá carteles, presentaciones orales y conferencias magistrales. La preinscripción e inscripción se pueden hacer en la página web. Las cuotas de inscripción son las siguientes: delegados: US\$ 225 (\$200 antes del 31 de diciembre del 2004); estudiantes: $\$ 150$ (\$125 antes del 31 de diciembre del 2004); acompañantes: \$50 (\$40 antes del 31 de diciembre del 2004).

Información:

Migdalia Luna Cisneros

Palacio de las Convenciones

Apartado Postal 16046

La Habana, Cuba

Teléfonos: (537) 285199 y 226011-19

Faxes: 287996, 283470 y 238382

Correo electrónico: migdalia@palco.cu http://www.complejopalco.com

Internet: http://www.loseventos.cu/seminariocnic2005 / http://www.cnic.edu.cu/14\%20Seminario/Bienvenida.htm 